\title{
Variations in layer 2A thickness and the origin of the central anomaly magnetic high
}

\author{
Jeff Gee and Dennis V. Kent \\ Lamont-Doherty Earth Observatory
}

Abstract: The seismically determined off-axis thickening of the extrusive layer is apparently at odds with the magnetic anomaly high typically associated with the ridge crest. The positive magnetization contrast at the ridge crest is most likely caused by rapid alteration of the extrusive source layer which occurs over spatial scales $(2-3 \mathrm{~km})$ comparable to that of the proposed Layer 2A thickening. We present magnetic remanence data from basalts dredged on and near the East Pacific Rise axis at $12^{\circ} \mathrm{N}$ which are compatible with a rapid magnetization reduction $(\sim 20 \mathrm{k}$.y. to decay to $1 / \mathrm{e})$. Together with near bottom magnetic profiles from the ultra-fastspreading East Pacific Rise at $19.5^{\circ} \mathrm{S}$, these data suggest that previous estimates of the time constant of alteration inferred from slow-spreading ridges $(0.5 \mathrm{~m} . \mathrm{y}$.) may be more than an order of magnitude too high.

Seismic studies of the fast-spreading East Pacific Rise (EPR) indicate a rapid thickening of seismic Layer $2 \mathrm{~A}$ within a few kilometers of the ridge axis [Vera et al., 1990; Toomey et al., 1990; Detrick et al, 1993]. These seismic data have been interpreted to reflect an approximate doubling of the extrusive layer thickness, from $\sim 100-200 \mathrm{~m}$ to $300-500 \mathrm{~m}$, through addition of flows which may extend 1-2 km off-axis [Christeson et al., 1992; Vera and Diebold, in press]. Such thickening of the extrusive source layer had been argued on the basis of the widths of magnetic reversal transitions [e.g., Macdonald et al., 1983]. However, this geometry for a uniformly magnetized source layer should produce a marked magnetic anomaly minimum over the ridge axis and is therefore difficult to reconcile with the pronounced anomaly high typically associated with the ridge crest [Klitgord, 1976].

Sea surface magnetic profiles from the ultra-fast-spreading (77 mm/yr half rate) EPR near $19.5^{\circ} \mathrm{S}$ (Figure 1) illustrate the short wavelength axial anomaly high within the $\sim 120 \mathrm{~km}$ wide Central Anomaly which has been termed the Central Anomaly magnetic high [CAMH; Klitgord, 1976]. The CAMH typically has a wavelength of $8-10 \mathrm{~km}$ in sea surface profiles. At intermediate-spreading ridges $(15-45 \mathrm{~mm} / \mathrm{yr})$ the CAMH occupies a larger proportion of the Central Anomaly, and at slow-spreading ridges it is not readily distinguishable in sea surface profiles from the Central Anomaly because the wavelengths become similar. Near bottom magnetic profiles (Figure 1) typically have higher amplitude and shorter wavelength (2-4 km) axial anomalies as expected from the closer proximity to the source [Klitgord et al., 1975; Miller, 1977; Perram et al., 1990] and even allow distinction of the CAMH from the Central Anomaly at some slow-spreading ridges [Macdonald, 1977]. The higher temporal resolution of faster spreading ridges therefore provides the best opportunity to evaluate the processes responsible for the CAMH.

Thickness variations in the extrusive layer at fast-spreading ridges have a profound effect on the axial magnetic anomaly, since the presence of an axial magma chamber and the low remanent intensity of intrusive rocks [e.g. Smith and Banerjee, 1986; Pariso et al., 1991] minimize deeper source contributions in the near-ridge environment. Based on seismic

Copyright 1994 by the American Geophysical Union.

Paper number 93GL03422

0094-8534/94/93GL-03422\$03.00 constraints from the southern EPR [Detrick et al., 1993; Xu et al., 1992], we generated forward models in which the extrusive source layer thickens from $200 \mathrm{~m}$ on-axis to $450 \mathrm{~m}$ by $3 \mathrm{~km}$ off-axis and with an axial magma chamber at a depth of $\sim 1.3 \mathrm{~km}$ (Figure 2). The mean magnetization $(20 \mathrm{~A} / \mathrm{m}$ ) assigned to the extrusive layer is based on intensities of dredged samples from $19.5^{\circ} \mathrm{S}$ [Sempere et al., 1988] and is compatible with the anomaly amplitude at the Brunhes/Matuyama boundary. The resulting sea surface anomaly is of comparable magnitude $(50 \mathrm{nT})$ and wavelength $(8-10 \mathrm{~km})$ to the observed CAMH but of the opposite sign. A simple half space cooling model for the intrusive portion of the crust (dikes and gabbros) results in an effective off-axis thickening of this potential source, as defined by the $600^{\circ} \mathrm{C}$ isotherm, which is analogous to the physical thickening of the extrusive layer. Contributions from deeper magnetic sources therefore also produce axial anomaly lows, although of longer wavelength and smaller amplitude than that produced by the extrusive layer (Figure 2).

Several factors may be invoked to explain the positive magnetic contrast generating the CAMH including geochemical variations [Prévot and Lecaille, 1976; Vogt and Johnson, 1973], bathymetric variations [Rea and Blakely, 1975], paleointensity variations, and changes in the source layer magnetization due to alteration [Klitgord et al., 1975; Tivey and Johnson, 1987]. Geochemical variations are an unlikely cause of the CAMH since this would require regionally, if not globally, synchronous changes in basalt chemistry. Topographic effects at fast-spreading ridges produce low amplitude variations $(-20 \mathrm{nT})$ but are insufficient to account for the CAMH. Sedimentary paleointensity records [e.g. Tric et al., 1992; Meynadier et al., 1992] show that the geomagnetic field intensity over the past $\sim 100 \mathrm{ka}$ was generally lower than the present field or the mean intensity over the entire $0.78 \mathrm{Ma}$ Brunhes [McFadden and McElhinny, 1982]; there is however an approximately threefold decrease in paleointensity from 3 to $20 \mathrm{ka}$. A magnetic source layer modeled with this geomagnetic intensity variation produces an overall axial anomaly low; a superimposed relative axial high is apparent only at half spreading rates greater than -25 $\mathrm{mm} / \mathrm{yr}$. Thus, the most probable general explanation of the magnetization contrast at the $\mathrm{CAMH}$ is rapid alteration of the source layer.

Analysis of near bottom magnetic profiles [Macdonald, 1977] and paleomagnetic studies of samples from the slowspreading ( $\sim 7 \mathrm{~mm} / \mathrm{yr}$ half rate) Mid-Atlantic Ridge [Irving, 1970; Johnson and Atwater, 1977] have previously documented a fivefold decrease in natural remanent magnetization (NRM) intensity within about $3 \mathrm{~km}$ of the axis. Systematic changes in rock magnetic properties accompanying this magnetization decrease have been interpreted as manifestations of low-temperature alteration. The corresponding time constant of magnetization decay, with an exponential form as expected for a diffusion limited process [e.g. Ozima et al., 1974], has long been inferred to be $\sim 0.5$ m.y.

Deep-Tow magnetic anomaly data from intermediate to fastspreading ridges require a reduction in magnetization of shallow sources also within a few kilometers of the ridge axis. Although this decay has been attributed to rapid lowtemperature alteration of the extrusive layer [Klitgord, 1976] it would correspond to much shorter time scales than derived from studies of the slow-spreading Atlantic. The general idea 

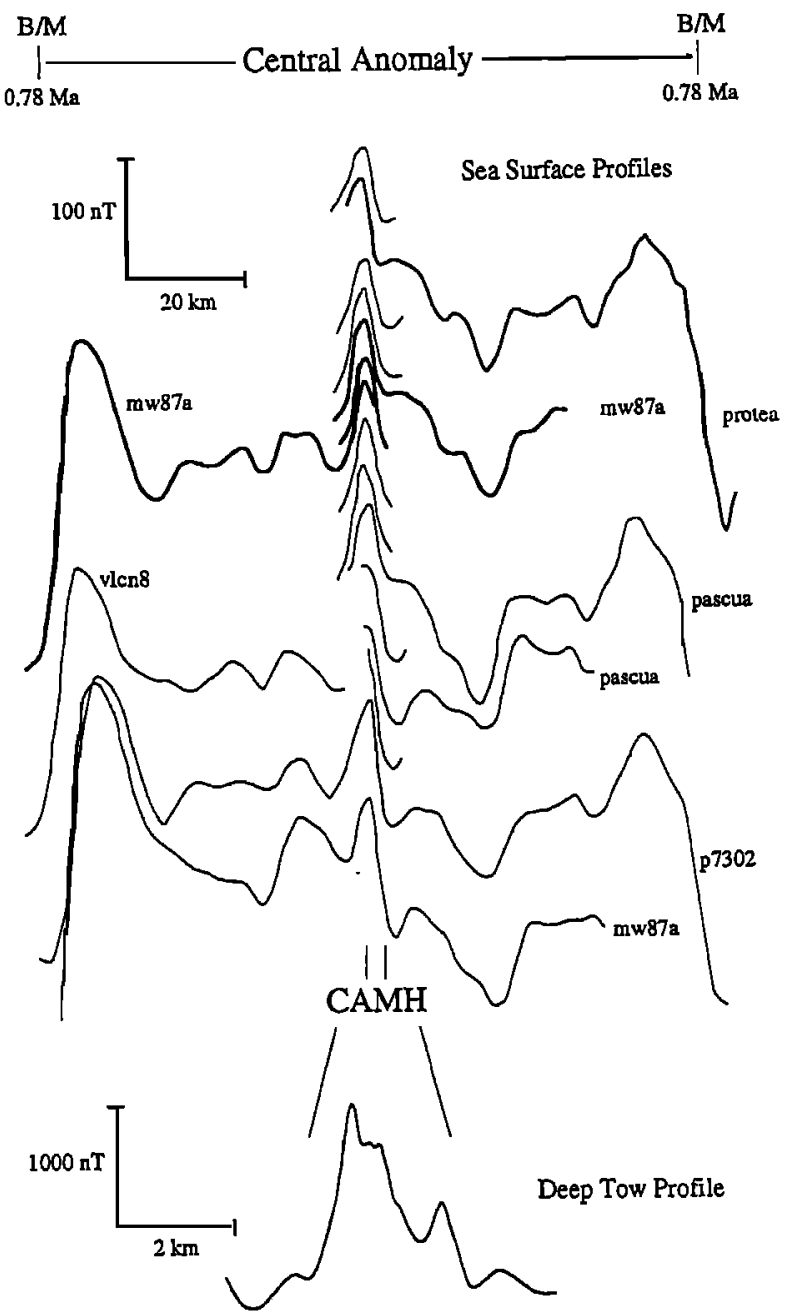

Fig. 1. Sea surface magnetic anomaly profiles of the Central Anomaly and upward continued axial Deep Tow profile (digitized from Perram et al., 1990) from $19.5^{\circ} \mathrm{S}$ on East Pacific Rise. Note the consistency of the Central Anomaly magnetic high (CAMH) both in amplitude (80-100 nT) and wavelength $(-8 \mathrm{~km})$ in all sea surface profiles. The CAMH on the near bottom profile is higher amplitude and shorter wavelength and includes an even shorter wavelength anomaly minimum which may reflect the thickening of Layer $2 \mathrm{~A}$. Sea surface profiles (labelled with cruise designation) are all from a $20 \mathrm{~km}$ section of the EPR. The profiles in bold are used as representative profile in subsequent figures. Profiles in this and subsequent figures have not been reduced to the pole.

that low-temperature alteration may account for rapid magnetization changes has been incorporated in subsequent studies [Perram et al., 1990; Sempere et al., 1990; Tivey and Johnson, 1987], however, there is a conspicuous lack of published data with temporal resolution sufficient to test this idea. We have examined one of the few dredge collections (near $12^{\circ} \mathrm{N}$ on the EPR) presently available with suitable offaxis coverage to assess the rapid alteration inferred from magnetic anomaly data.

Remanence data from these samples provide independent support for a rapid time constant for alteration of the magnetic source layer. NRM intensities and susceptibilities were determined for 21 samples ( 81 specimens) from 13 dredges collected between $12^{\circ} 03^{\prime} \mathrm{N}$ and $12^{\circ} 12^{\prime} \mathrm{N}$ on the EPR. The most striking feature of the NRM data is the large variability evident in "zero-age" lavas (Figure 3a). A similar variation in initial susceptibility (Figure $3 \mathrm{~b}$ ) provides additional evidence that intrinsic rock magnetic properties, rather than geomagnetic intensity variations, are mainly responsible for the decrease in NRM intensity with distance from the axis. Localized hydrothermal alteration [Tivey et al., 1993] or geochemical variations [Prévot and Lecaille, 1976; Vogt and Johnson, 1973] may be contributing factors, however, we suggest that rapid low-temperature alteration together with the inherent age uncertainty in dredged samples provides an adequate explanation of the observed NRM variability. The lower NRM intensities of a limited number of samples within $10 \mathrm{~km}$ of the axis and the consistently low intensities of older dredged and drilled material provide further support for this interpretation. Curie temperatures of samples from $12^{\circ} \mathrm{N}$ also show a correspondingly large variation $\left(100^{\circ}-300^{\circ} \mathrm{C}\right)$ although they are not simply related to NRM intensity. Although commonly taken as the hallmark of low-temperature oxidation, elevated bulk Curie temperatures are evidently not an adequate indicator of the alteration state of the remanence carrying fraction and
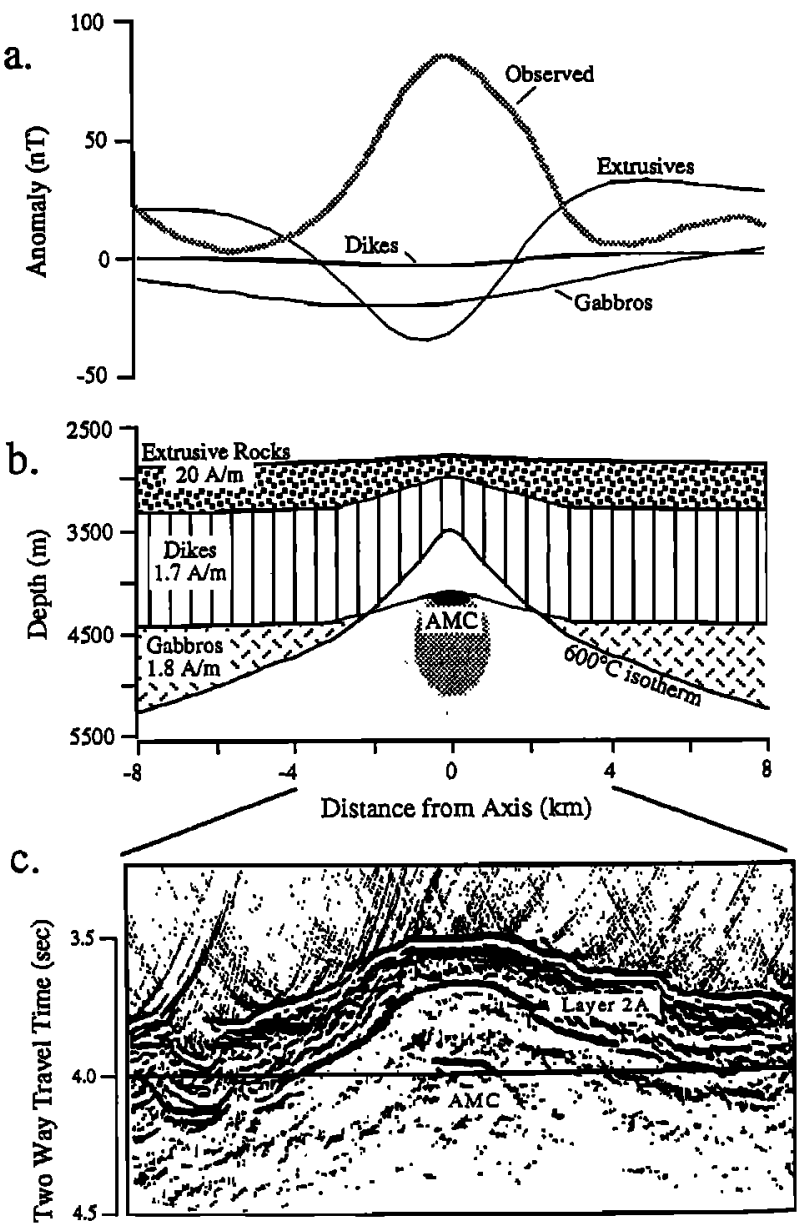

Fig. 2. (a) Forward models illustrating the axial magnetic anomaly minimum generated by off-axis thickening of a uniformly magnetized extrusive layer or cooling of deeper layers as shown in (b), compared to the observed sea surface profile at $19.5^{\circ} \mathrm{S}$ on EPR. (b). Source model based on seismic data from near $19.5^{\circ} \mathrm{S}$ that indicate thickening of Layer $2 \mathrm{~A}$ from $200 \mathrm{~m}$ to $450 \mathrm{~m}$ within $1-3 \mathrm{~km}$ of the axis [Xu et al., 1992; P. Buhl, pers. comm., 1993] and axial magma chamber at $\sim 1.3 \mathrm{~km}$ [Detrick et al., 1993]. Magnetization values for intrusives from Smith and Banerjee [1986] and Pariso et al. [1991]; $600^{\circ} \mathrm{C}$ isotherm based on half space cooling model, modified to account for the presence of a steady state magma chamber (black). (c) Wide aperture seismic profile from EPR near $14^{\circ} \mathrm{S}$ [from Detrick et al., 1993] illustrates rapid thickening of Layer $2 \mathrm{~A}$ and presence of axial magma chamber (AMC). 

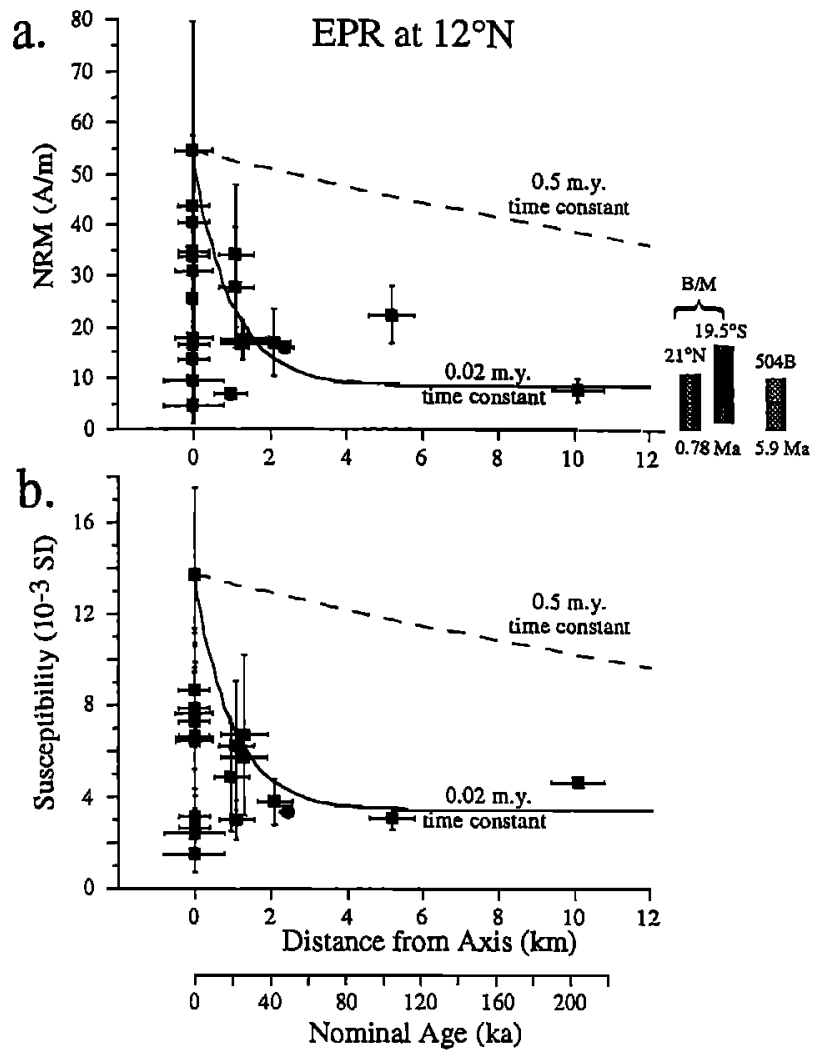

thickest on axis at some slow to intermediate spreading ridges [Macdonald et al., 1993].

Given the revised estimate for a short time constant of alteration, near bottom magnetic anomaly data may potentially be used to assess a variety of ridge crest processes. For example, Perram et al. [1990] noted a very short wavelength axial low within the CAMH in near bottom profiles from $19.5^{\circ} \mathrm{S}$ (Figure 1) which they modeled with a thinned source layer due to elevated temperature. A similar feature observed at the Endeavor Ridge has been attributed to focussing of lowtemperature alteration by crustal fissuring [Tivey and Johnson, 1987]. Thickening of Layer $2 \mathrm{~A}$, together with rapid alteration of the extrusive layer, provides an alternative explanation: the profile from $19.5^{\circ} \mathrm{S}$ can also be modeled adequately using a Layer $2 \mathrm{~A}$ which thickens from 200 to $450 \mathrm{~m}$ by $3 \mathrm{~km}$ off-axis, and an exponential magnetization decay with an approximately $300 \mathrm{~m}$ wide neovolcanic zone in which magnetization is constant (Figure 4). Forward modeling indicates that the

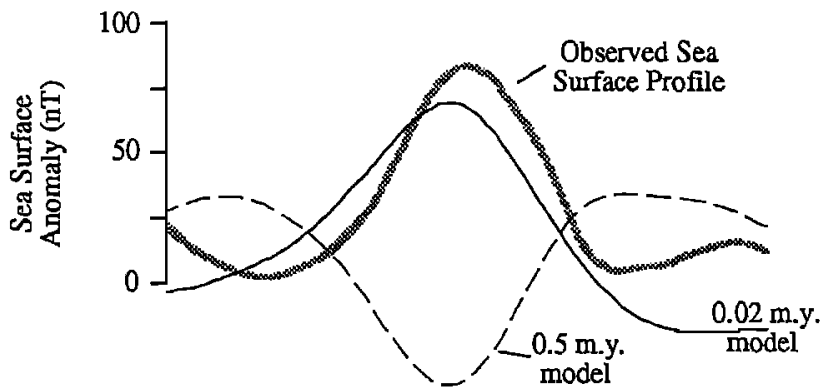

Fig. 3. Natural remanent magnetization (a) and susceptibility variation (b) for samples from $12^{\circ} \mathrm{N}$ on EPR as a function of distance from the ridge axis. NRM and susceptibility data (with $1 \sigma$ error) from $12^{\circ} \mathrm{N}$ are for individual samples. Each data point is the average of 3-6 specimens collected within 5-8 $\mathrm{cm}$ of the glassy margin. An exponential magnetization decay with a time constant of $20 \mathrm{k}$.y., as suggested by near bottom magnetic profiles from the ultra-fast-spreading EPR at $19.5^{\circ} \mathrm{S}$, provides a better match to the observed NRM and susceptibility variation at $12^{\circ} \mathrm{N}$ than the $0.5 \mathrm{~m}$.y. time constant inferred from studies of the slow-spreading Mid-Atlantic Ridge. NRM intensities (reduced to a common latitude of $12^{\circ} \mathrm{N}$ ) of samples dredged near the Brunhes/Matuyama boundary at the EPR [Sempere et al., 1988] and extrusive rocks sampled at DSDP/ODP Hole 504B ( $\sim 6 \mathrm{Ma}$ crust [Smith and Banerjee, 1986]) are representative of the lower intensities found in older dredged and drilled material.

hence variations in NRM intensity [cf. Johnson and Atwater, 1977].

Models incorporating the seismically-determined variation in the thickness of Layer $2 \mathrm{~A}$ at ultra-fast-spreading ridges convincingly demonstrate that the $0.5 \mathrm{~m}$.y. time constant of magnetization reduction based on observations at the slowspreading Mid-Atlantic Ridge is too long by more than an order of magnitude (Figure 4). The width of the CAMH $(\sim 3$ $\mathrm{km}$ ) in near-bottom profiles from the ultra-fast-spreading EPR at $19.5^{\circ} \mathrm{S}(77 \mathrm{~mm} / \mathrm{yr}$ half rate [Perram et al., 1990]) may provide the best estimate of the time constant of alteration of nominally $20 \mathrm{k} . y$. , a value compatible with the magnetization reduction inferred from the samples at the fast-spreading EPR at $12^{\circ} \mathrm{N}(49 \mathrm{~mm} / \mathrm{yr}$ half rate [Perram and Macdonald, 1990], recalculated assuming an age of $0.78 \mathrm{Ma}$ for the Brunhes [Cande and Kent, 1992]). The lower effective temporal resolution at the slow-spreading Mid-Atlantic Ridge may be attributed to the substantial size of individual volcanic constructional features (up to $1-2 \mathrm{~km}$ width [Macdonald, 1977; Smith and Cann, 1992]) relative to total width of the Central Anomaly $(\sim 10 \mathrm{~km})$. The volcanic layer may even be locally
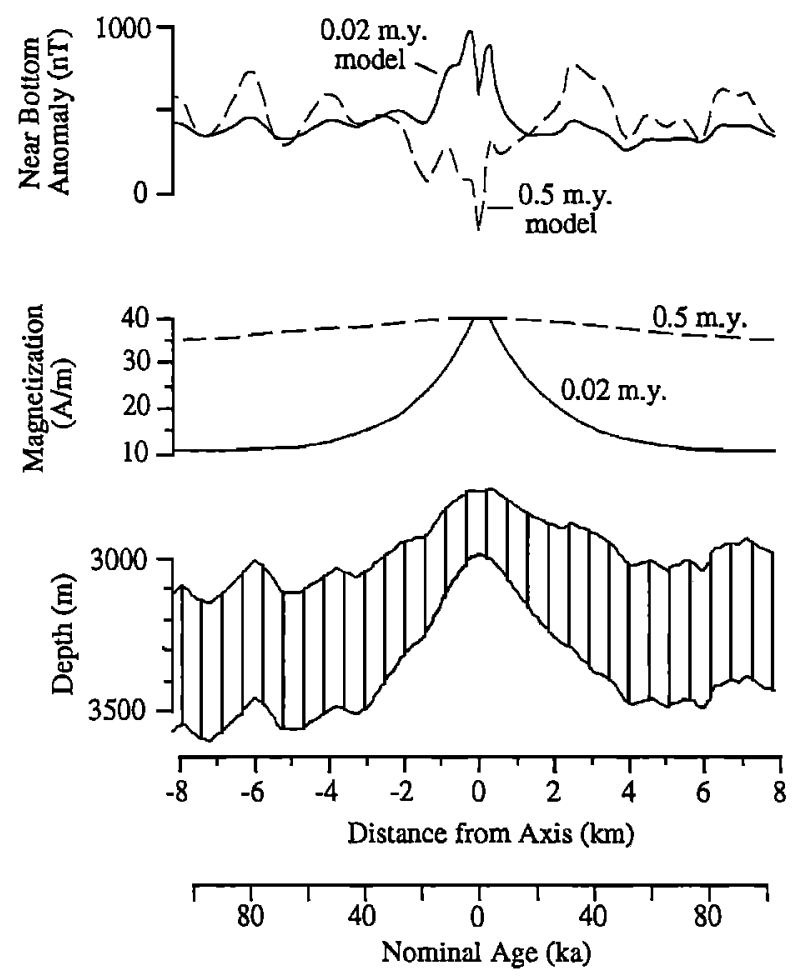

Fig. 4. Forward models incorporating off-axis thickening of the source layer. A time constant of $0.5 \mathrm{~m}$.y. as inferred from observations at the Mid-Atlantic Ridge produces a negative anomaly in both the sea surface and near bottom profiles (upward continued to $2700 \mathrm{~m}$ ). A $20 \mathrm{k} . \mathrm{y}$. time constant together with a $300 \mathrm{~m}$ neovolcanic zone adequately matches the observed sea surface profile as well as the shorter wavelength minimum within the CAMH in the near bottom profile (see Figure 1). Seismic data from the EPR near $19.5^{\circ} \mathrm{S}$ [Xu et al., 1992; P. Buhl, pers. comm., 1993] indicate thickening of Layer $2 \mathrm{~A}$ from $200 \mathrm{~m}$ to $450 \mathrm{~m}$ by $3 \mathrm{~km}$ from the ridge axis. 
amplitude of the Deep-Tow axial high and the superimposed shorter wavelength minimum are very sensitive to the magnetization magnitude and decay rate relative to the thickening of Layer 2A. Although rapid changes in the magnetization of the sheeted dikes cannot be entirely excluded, low-temperature alteration of the extrusive layer provides an established mechanism for this time-dependent magnetization reduction. We therefore suggest that better characterization of the lateral magnetization variation through detailed sampling should provide an independent assessment of the thickening of Layer 2A imaged seismically.

Acknowledgements. We thank C. H. Langmuir, J. F. Bender, and J. R. Reynolds for providing samples, S. P. Miller for providing a forward modeling program, and $H$. $P$. Johnson and K. C. Macdonald for helpful comments which improved the manuscript. Lamont-Doherty Earth Observatory contribution \#5157.

\section{References}

Cande, S. C., and D. V. Kent, A new geomagnetic polarity time scale for the Late Cretaceous and Cenozoic, $\mathbf{L}$ Geophys. Res., 97 13,917-13,951, 1992.

Christeson, G. L., G. M. Purdy, and G. J. Fryer, Structure of young upper crust at the East Pacific Rise near $9^{\circ} 30^{\prime} \mathrm{N}$, Geophys. Res. Lett., 19, 1045-1048, 1992.

Detrick, R. S., A. J. Harding, G. M. Kent, J. A. Orcutt, J. C. Mutter, and P. Buhl, Seismic structure of the southern East Pacific Rise, Science, 259, 499-503, 1993.

Irving, E., The Mid-Atlantic Ridge at $45^{\circ} \mathrm{N}$. XIV. Oxidation and magnetic properties of basalt; review and discussion, Can. J. Earth Sci., Z, 1528-1538, 1970.

Johnson, H. P., and T. Atwater, Magnetic study of basalts from the Mid-Atlantic Ridge, lat $37^{\circ} \mathrm{N}$, Geol. Soc. Amer. Bull, 88, 637-647, 1977.

Klitgord, K. D., Sea-floor spreading: the central anomaly magnetization high, Earth Planet. Sci. Lett. 29, 201-209, 1976.

Klitgord, K. D., S. P. Huestis, J. D. Mudie, and R. L. Parker, An analysis of near-bottom magnetic anomalies: sea-floor spreading and the magnetized layer, Geophys.J. R. astr. Soc., 43, 387-424, 1975.

Macdonald, K. C., Near-bottom magnetic anomalies, asymmetric spreading, oblique spreading, and tectonics of the Mid-Atlantic Ridge near lat $37^{\circ} \mathrm{N}$, Geol. Soc. Amer. Bull. 88, 541-555, 1977.

Macdonald, K. C., S. P. Miller, B. P. Luyendyk, T. M. Atwater, and L. Shure, Investigation of a Vine-Matthews magnetic lineation from a submersible: The source and character of marine magnetic anomalies, J. Geophys. Res.. 88, 3403-3418, 1983.

Macdonald, K. C., D. S. Sheirer, S. Carbotte, and P. J. Fox, It's only topography: Part 2, GSA Today, 3, 29-34, 1993.

McFadden, P. L., and M. W. McElhinny, Variations in the geomagnetic dipole 2: statistical analysis of VDMs for the past 5 million years, J. Geomag. Geoelectr., 34, 163-189, 1982.

Meynadier, L., J.-P. Valet, R. Weeks, N. J. Shackleton, and V. L. Hagee, 1992, Relative geomagnetic intensity of the field during the last $140 \mathrm{ka}$, Earth Planet. Sci. Lett., 114. 39-57.

Miller, S. P., The validity of the geological interpretations of marine magnetic anomalies, Geophys. J. R. astr. Soc., 50. 1-21, 1977.

Ozima, M., M. Joshima and H. Kinoshita, 1974, Magnetic properties of submarine basalts and the implications on the structure of the oceanic crust, J. Geomag. Geoelectr. 26. 335-354.

Pariso, J. E., J. H. Scott, E. Kikawa and H. P. Johnson, A magnetic logging study of Hole 735B gabbros at the Southwest Indian Ridge, Proc. Ocean Drill. Prog., Sci. Res., 118, 309-321, 1991..

Perram, L. J., and K. C. Macdonald, A one-million-year history of the $11^{\circ} 45^{\prime} \mathrm{N}$ East Pacific Rise discontinuity, $\mathrm{L}$ Geophys. Res., 95, 21,363-21,381, 1990.

Perram, L. J., K. C. Macdonald, and S. P. Miller, Deep-Tow magnetics near $20^{\circ} \mathrm{S}$ on the East Pacific Rise: A study of short wavelength anomalies at a very fast spreading center, Mar. Geophys. Res., 12, 235-245, 1990.

Prévot, M., and A. Lecaille, Comments on paper by K.D. Klitgord, "Sea-floor spreading: the central anomaly magnetization high", Earth Planet. Sci. Lett., 33, 164-168, 1976.

Rea, D. K., and R. J. Blakely, Short-wavelength magnetic anomalies in a region of rapid seafloor spreading, Nature. 255, 126-128, 1975.

Sempere, J.-C., A. Meshkov, M. Thommeret, and K. Macdonald, Magnetic properties of some young basalts from the East Pacific Rise, Mar. Geophys. Res., 2, 131$146,1988$.

Sempere, J.-C., L. Kristjansson, H. Schouten, J. R. Heirtzler, and G. L. Johnson, A detailed magnetic study of the Reykjanes Ridge between $63^{\circ} 00^{\prime} \mathrm{N}$ and $63^{\circ} 40^{\prime} \mathrm{N}$, Mar. Geophys. Res., 12, 215-234, 1990.

Smith, D.K. and J. R. Cann, The role of seamount volcanism in crustal construction at the Mid-Atlantic Ridge (24\%$30^{\circ} \mathrm{N}$ ), J. Geophys. Res., 97, 1645-1658, 1992.

Smith, G. M., and S. K. Banerjee, Magnetic structure of the upper kilometer of the marine crust at Deep Sea Drilling Project Hole 504B, Eastern Pacific Ocean, J. Geophys. Res., 91, 10,337-10,354, 1986.

Tivey, M. A., and H. P. Johnson, The central anomaly magnetic high: implications for ocean crust construction and evolution, I. Geophys. Res., 22 . 12,685-12,694, 1987.

Tivey, M. A., P. A. Rona, and H. Schouten, Reduced crustal magnetization beneath the active sulfide mound, TAG hydrothermal field, Mid-Atlantic Ridge at $26^{\circ} \mathrm{N}$, Earth Planet. Sci. Lett., 115, 101-115, 1993.

Toomey, D. R., G. M. Purdy, S. C. Solomon and W. S. D. Wilcock, The three-dimensional seismic velocity structure of the East Pacific Rise near latitude $9^{\circ} 30^{\prime} \mathrm{N}$, Nature, 347 639-645, 1990.

Tric, E., J.-P. Valet, P. Tucholka, M. Paterne, L. Labeyrie, F. Guichard, L. Tauxe and M. Fontugne, 1992, Paleointensity of the geomagnetic field during the last 80,000 years, I. Geophys. Res., 97, 9337-9351.

Vera, E. E., and J. B. Diebold, Seismic imaging of oceanic layer $2 \mathrm{~A}$ between $9^{\circ} 30^{\prime} \mathrm{N}$ and $10^{\circ} \mathrm{N}$ on the East Pacific Rise from two-ship wide aperture profiles, J. Geophys. Res., in press.

Vera, E. E., J. C. Mutter, P. Buhl, J. A. Orcutt, A. J. Harding, M. E. Kappus, R. S. Detrick, and T. M. Brocher, The structure of 0 - to 0.2-m.y.-old oceanic crust at $9^{\circ} \mathrm{N}$ on the East Pacific Rise from expanded spread profiles, I. Geophys. Res. 95, 15,529-15,556, 1990.

Vogt, P. R., and G. L. Johnson, Magnetic telechemistry of oceanic crust?, Nature, 245, 373-375, 1973.

Xu, L., J. C. Mutter, P. Buhl, R. S. Detrick, J. Orcutt, G. Kent, and A. Harding, Substructure of an inflated region. of the East Pacific Rise at $17^{\circ} 25^{\prime S}$ (abstract), Eos Trans. AGU, 73, 494, 1992.

J. Gee and D.V. Kent, Lamont-Doherty Earth Observatory of Columbia University, Palisades, NY 10964.

(Received August 31, 1993; revised November 22; accepted December 1, 1993.) 